\title{
Photoelectrocatalytic Degradation of Organic Pollutants in Aqueous Solution Using a Pt-TiO 2 Film
}

\author{
Chun He, ${ }^{1}$ Mudar Abou Asi, ${ }^{1}$ Ya Xiong, ${ }^{1}$ Dong Shu, ${ }^{2}$ and Xiangzhong $\mathrm{Li}^{3}$ \\ ${ }^{1}$ School of Environmental Science and Engineering, Sun Yat-sen University, Guangzhou 510275, China \\ ${ }^{2}$ Key Lab of Electrochemical Technology on Energy Storage and Power Generation in Guangdong Universities, \\ School of Chemistry and Environment, South China Normal University, Guangzhou 510006, China \\ ${ }^{3}$ Department of Civil and Structural Engineering, The Hong Kong Polytechnic University, Hong Kong, China \\ Correspondence should be addressed to Chun He, hechun@mail.sysu.edu.cn
}

Received 1 April 2009; Accepted 27 June 2009

Recommended by Mohamed Sabry Abdel-Mottaleb

A series of $\mathrm{Pt}-\mathrm{TiO}_{2}$ films with nanocrystaline structure was prepared by a procedure of photodeposition and subsequent dip-coating. The $\mathrm{Pt}-\mathrm{TiO}_{2}$ films were characterized by X-ray diffraction, scanning electronic microscope, electrochemical characterization to examine the surface structure, chemical composition, and the photoelectrochemical properties. The photocatalytic activity of the $\mathrm{Pt}-\mathrm{TiO}_{2}$ films was evaluated in the photocatalytic (PC) and photoelectrocatalytic (PEC) degradation of formic acid in aqueous solution. Compared with a $\mathrm{TiO}_{2}$ film, the efficiency of formic acid degradation using the Pt-TiO $\mathrm{films}$ was significantly higher in both the $\mathrm{PC}$ and $\mathrm{PEC}$ processes. The enhancement is attributed to the action of $\mathrm{Pt}$ deposits on the TiO 2 surface, which play a key role by attracting conduction band photoelectrons. In the PEC process, the anodic bias externally applied on the illuminated $\mathrm{Pt}-\mathrm{TiO}_{2}$ films can further drive away the accumulated photoelectrons from the metal deposits and promote a process of interfacial charge transfer.

Copyright ( 92009 Chun He et al. This is an open access article distributed under the Creative Commons Attribution License, which permits unrestricted use, distribution, and reproduction in any medium, provided the original work is properly cited.

\section{Introduction}

The widespread pollution of drinking water or effluents from industries and household with hazards and biorecalcitrant organic compounds demands an increasing effort towards the development of technologies for the cleanup of such wastewater $[1,2]$. In past decades heterogeneous photocatalysis using $\mathrm{TiO}_{2}$ has been attracted much attention in the field of environmental research for the degradation of undesirable organics in aqueous solution $[3,4]$. The appeal of this technology is the prospect of complete mineralization of the pollutants into harmless compounds to environment in addition to the abundance, relatively low cost, chemical stability, and nontoxic nature of the catalyst. However, the PC efficiency is limited by the high degree of electron-hole recombination $[5,6]$.

Recently many studies have been devoted to improving $\mathrm{PC}$ activity by modifying $\mathrm{TiO}_{2}$ using the deposition of noble metals [7-10]. In these cases, a Schottky barrier between the metal and $\mathrm{TiO}_{2}$ is formed, while both metal and $\mathrm{TiO}_{2}$
Fermi levels equilibrate. Upon irradiation, the conduction band electrons flow from $\mathrm{TiO}_{2}$ to the deposited metal that can act as a sink for the photogenerated electrons. This migration of the generated electrons to metal particles, on the one hand, can increase the lifetime of holes and suppress the electron-hole recombination, thus favoring PC oxidation of organic pollutants $[7,8,10]$; on the other hand, the migration can also enhance the $\mathrm{PC}$ reductive activity of $\mathrm{TiO}_{2}$ $[11,12]$. The reduction of organic pollutant is a process of increasing COD, generally unbeneficial to environmental protect. Moreover, the positive-charged holes, negativecharged metal particles, and organic pollutants are in a same reaction system; as a result, the system possibly suffers from a disadvantage that the intermediates of oxidized organic pollutants are re-reduced, leading to the formation of shortcircuit similar to the mechanism of $\mathrm{TiO}_{2}$ deactivation by chlorine ions [13] because any species with a reduction potential more positive than the flat band potential of $\mathrm{TiO}_{2}$ $(\sim-0.7 \mathrm{~V}$ versus SCE, at $\mathrm{pH} 7)$, in theory, can be reduced [14]. In fact, recently many authors have demonstrated 


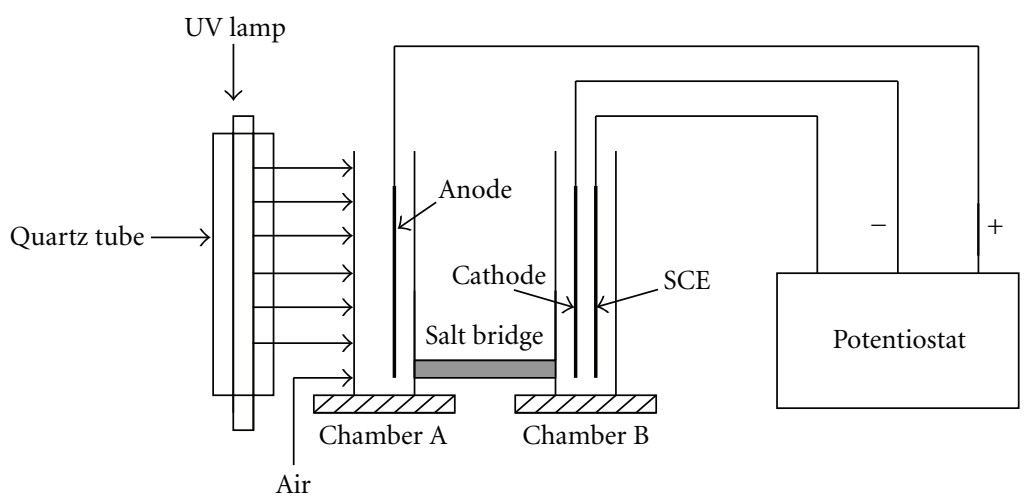

FIGURE 1: Schematic diagram of PC and PEC photoreactor systems.

that the PC oxidation activity of the metallized $\mathrm{TiO}_{2}$ is comparable to, and what is more, less than that of native $\mathrm{TiO}_{2}$ [15-17].

Based on the above considerations, it is significant for the oxidation of organic pollutants to further transfer the migrated electrons on the metal particles out of the reaction system by the alternatively externally applied anodic bias; the process is addressed as PEC one [18]. The externally anodic bias potential on the illuminated metal-loaded $\mathrm{TiO}_{2}$ film cannot only spatially separate the capture of conduction band electrons from the oxidation process but also drive away the accumulated photogenerated electrons on metal particles to another compartment of cell. Although many efforts have been directed to the PEC degradation of organic pollutants on $\mathrm{TiO}_{2}$ film [19-23], to date, rare information is available on the PEC oxidation of organic pollutants on metal-loaded $\mathrm{TiO}_{2}$ film except our recent reported examples [24, 25]. The above-mentioned situation aroused us to make attempts to prepare a novel platinum-deposited titanium dioxide film, $\mathrm{Pt}-\mathrm{TiO}_{2}$ film, and to investigate photoelectrochemical performance of $\mathrm{Pt}-\mathrm{TiO}_{2}$ film electrode and $\mathrm{PEC}$ activity towards the oxidation of organic pollutants on $\mathrm{Pt}-\mathrm{TiO}_{2}$ film electrode.

\section{Experimental}

2.1. Materials. Photocatalyst was $\mathrm{TiO}_{2}$ (Degussa P25). Formic acid solution was $15 \mathrm{mmol}^{-1}$ (COD: $239 \mathrm{mgl}^{-1}$ ). ITO (indium-tin oxide) conductive glass plates were used as a support of platinised $\mathrm{TiO}_{2}$ film to conveniently perform photoelectrochemical measurements.

2.2. Preparation of $\mathrm{TiO}_{2}$ and $\mathrm{Pt}-\mathrm{TiO}_{2}$ Film. A TiO $/$ ITO film was first prepared according to the procedure described in literature [23], in which, $40 \mathrm{~g}$ of $\mathrm{TiO}_{2}$ powder was added into $500 \mathrm{~mL}$ of distilled water. The $\mathrm{TiO}_{2}$ slurry was sonicated for 30 minutes to break the loosely-attached aggregates up and then vigorously agitated to form fine $\mathrm{TiO}_{2}$ suspension. Then the $\mathrm{TiO}_{2}$ in the suspension was loaded on the ITO glass plate $(1.0 \mathrm{~cm} \times 5.0 \mathrm{~cm})$ by a procedure of dip-coating, drying, and sintering. The $\mathrm{TiO}_{2}$-coated ITO film was dried for 15 minutes on a hot plate at $100^{\circ} \mathrm{C}$ and subsequently sintered in a muffle furnace at $400^{\circ} \mathrm{C}$ for 2 hours to obtain the $\mathrm{TiO}_{2} / \mathrm{ITO}$ film. The quantity of $\mathrm{TiO}_{2}$ loading was about $1.07-1.10 \mathrm{mg} \mathrm{cm}^{-2}$.

$\mathrm{Pt}-\mathrm{TiO}_{2}$ film was prepared using a dip-coating procedure followed by $\mathrm{Pt}$ photodeposition. An aqueous suspension of $\mathrm{TiO}_{2}\left(80.0 \mathrm{gl}^{-1}\right)$ was sonicated 30 minutes before coating. The suspension was loaded on an ITO glass $(12 \mathrm{~cm} \times 4.8 \mathrm{~cm})$, dried 15 minutes on a hot plate at $100^{\circ} \mathrm{C}$ and then sintered 2 hours at $400^{\circ} \mathrm{C}$. The loading, drying, and sintering was repeated three times. The quantity of $\mathrm{TiO}_{2}$ was about $0.94-1.00 \mathrm{mg} \mathrm{cm}^{-2}$ by weighing. The resulting $\mathrm{TiO}_{2}$ plate was immersed in a $40-\mathrm{mL}$ aqueous solution containing $\mathrm{H}_{2} \mathrm{PtCl}_{6}\left(2.2 \mathrm{mmol}^{-1}\right)$ and $\mathrm{HCOOH}\left(1 \mathrm{~mol}^{-1}\right)$ and then subjected to photodeposition of Pt. The deposited Pt content was controlled under the different illumination time of 0.5 , $1.0,5.0,10.0$, and 20.0 minutes. An EDS analysis was carried out to confirm the amount of Pt content in the $\mathrm{TiO}_{2}$ films, which were $0.7 \%, 1.8 \%, 2.7 \%, 3.5 \%$, and $4.2 \%$ (Wt. Pt/ Wt. $\mathrm{TiO}_{2}$ ), respectively.

2.3. Characterization of $\mathrm{TiO}_{2} / \mathrm{ITO}$ and Metal-Deposited $\mathrm{TiO}_{2}$ Films. X-ray reflection diffraction (XRD) was performed using D/Max-IIIA Diffratometer (Rigaku Corporation, Japan) with Radiation of $\mathrm{Cu}$ target $(K \alpha 1, \lambda=1.54056 \mathrm{~nm})$. Scanning electron microscope (SEM) images were obtained on a JSM-6330F-mode Field Emission Scanning Electron Microscope (JEOL, Japan). A UV-PC3101PC spectrophotometer (SHIMASZU, Japan) was used for recording the UV absorption spectra of solution. Photoelectrochemical measurement was performed with a Model CH650 Potentiostat.

2.4. Experiments of $P C$ and PEC Oxidation. Formic acid chemical with analytical grade was supplied by Guangzhou Chemical Co. and used as a model chemical in this study. $15 \mathrm{mM}$ formic acid solution was first prepared with an initial COD concentration of $239 \mathrm{mg} \mathrm{L}^{-1}$ and $\mathrm{pH} 2.73$. About $35.0 \mathrm{~mL}$ of the $15 \mathrm{mM}$ formic acid solution was used in both the PC and PEC reactions. Both of PC and PEC oxidation reactions were carried out in a photoreactor system as shown in Figure 1, consisting of two chambers (A and B, $2.0 \mathrm{~cm} \times 1.1 \mathrm{~cm} \times 8.0 \mathrm{~cm}$ ) connected via a salt bridge. When the PC reaction was conducted using the chamber 


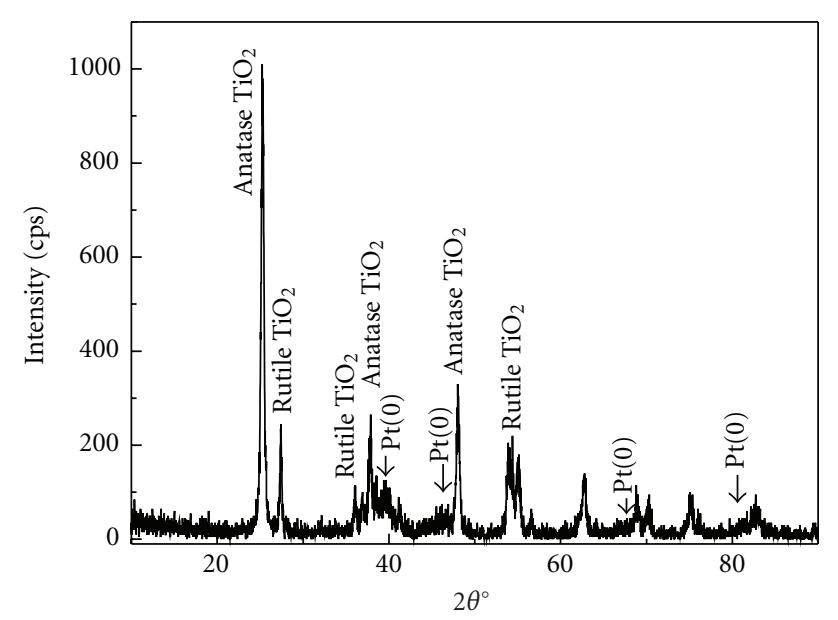

FIgURe 2: XRD spectra of Pt- $\mathrm{TiO}_{2}$.

A only, the PEC reaction was performed using both the champers. In the meantime, a 500-W UV lamp with main emission at $365 \mathrm{~nm}$ was used as a UV source, and air bubbling was continuously provided during reaction. Either the $\mathrm{TiO}_{2}$ or $\mathrm{Pt}-\mathrm{TiO}_{2}$ plate was placed in the chamber $\mathrm{A}$ and used as an anodic electrode, while a Pt electrode and a saturated calomel electrode (SCE) were positioned in the chamber B and used as counter and reference electrodes, respectively. The photoelectrochemical measurement was performed with a potentiostat (Model CH 650, Shanghai).

2.5. Analysis. Chemical oxygen demand (COD) was measured with potassium dichromate after the sample was digested with a WMX COD microwave digestion system [26].

\section{Results and Discussion}

3.1. Preparation and Characterization of Pt-TiO $\mathrm{O}_{2}$ Film. In our previous work, nano- $\mathrm{Ag}$ and $\mathrm{Cu}$ were successfully deposited on $\mathrm{TiO}_{2}$ film by photoreduction $[24,25]$. Herein, we also try to directly deposit $\mathrm{Pt}$ on the film surface by the same method, using $\mathrm{H}_{2} \mathrm{PtCl}_{6}$ as a $\mathrm{Pt}$ precursor and $\mathrm{HCOOH}$ as a hole scavenger, in order to prepare $\mathrm{Pt}-\mathrm{TiO}_{2}$ film. Upon illuminating $\mathrm{TiO}_{2}$ film inserted in the $\mathrm{H}_{2} \mathrm{PtCl}_{6}-\mathrm{HCOOH}$ solution, a layer of black deposits on the surface of $\mathrm{TiO}_{2}$ film was observed. The XRD pattern of the black deposits mixed with $\mathrm{TiO}_{2}$ was shown in Figure 2. Four weak and broad XRD peaks were observed at $2 \theta$ angles of $39.74,46.16,67.56$, and 80.98. The $2 \theta$ angles are corresponding to that of metallic $\mathrm{Pt}$, and the breadth of these peaks is characteristic of $\mathrm{Pt}$ nanocrystals $[9,27]$. Their average crystal size was calculated as $8 \mathrm{~nm}$ by using the Scherrer equation.

Figure 3 represents the SEM micrographs of the $\mathrm{TiO}_{2}$ and platinised films. The morphologies are noticeably dependent on the composition of films. $\mathrm{TiO}_{2}$ film was of highly porous and particulate surface (Figure 3(a)). The particulate size is estimated to be approximate $50 \mathrm{~nm}$, greater than that of the original $\mathrm{P} 25 \mathrm{TiO}_{2}$ powder $(30 \mathrm{~nm})$. The fact indicates that

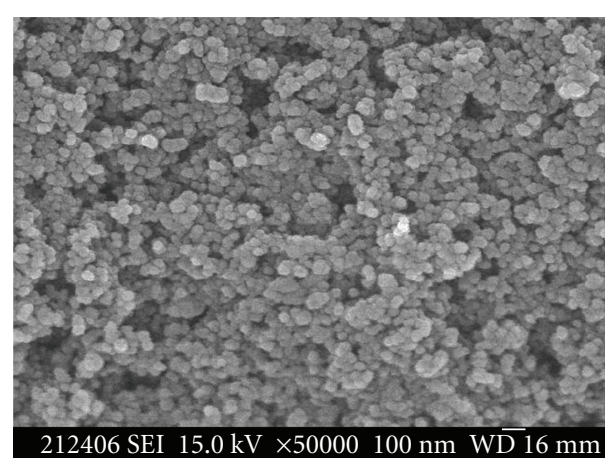

(a)

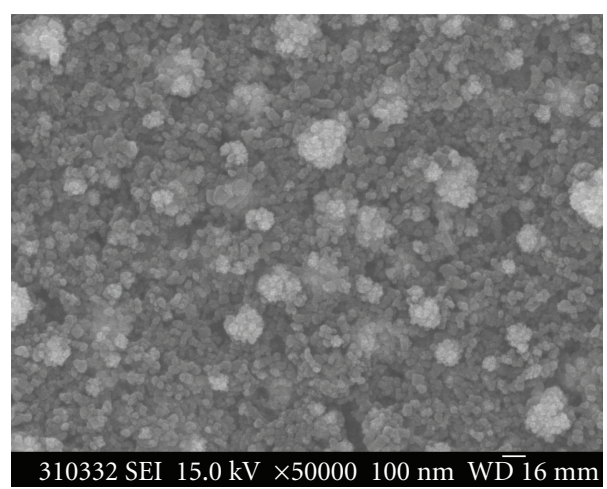

(b)

Figure 3: SEM images of $\mathrm{TiO}_{2}$ and $\mathrm{Pt}-\mathrm{TiO}_{2}$ films (a) $\mathrm{TiO}_{2}$ film and (b) $\mathrm{Pt}-\mathrm{TiO}_{2}$ with 1.8 wt.\% Pt.

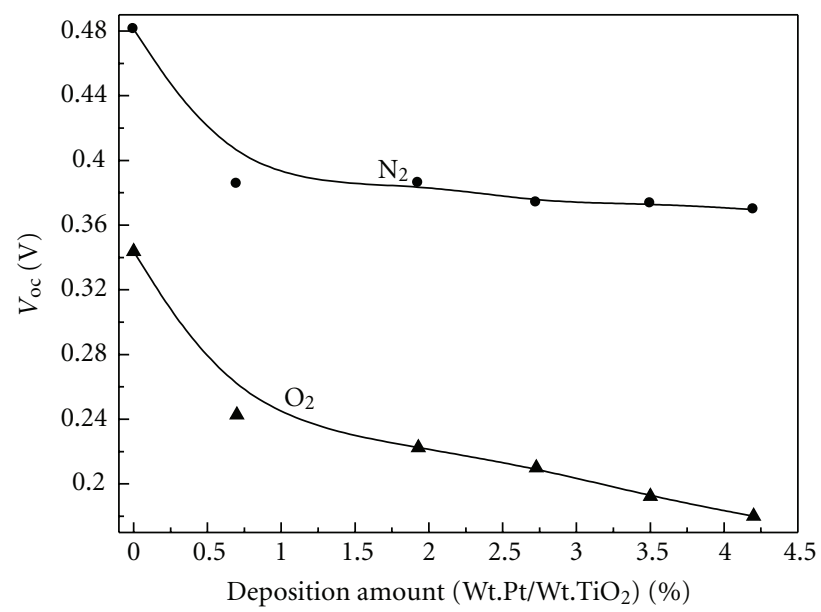

Figure 4: Change of $V_{\text {oc }}$ of $\mathrm{Pt}-\mathrm{TiO}_{2}$ with deposited Pt amount $\left(V_{\text {oc }}\left(\mathrm{N}_{2}\right)\right.$ for $\mathrm{N}_{2}$-saturated solution and $V_{\text {oc }}\left(\mathrm{O}_{2}\right)$ for $\mathrm{O}_{2}$-saturated solution).

the $\mathrm{TiO}_{2}$ particles were slightly aggregated during sintering. The surface of $\mathrm{Pt}-\mathrm{TiO}_{2}$ film is similar to that of $\mathrm{TiO}_{2}$ film (Figure 3(b)). It characterized a porous and particulate appearance, but the particulate size was smoother than that of the particulates on $\mathrm{TiO}_{2}$ film according to the resolution used; therefore, it means that the supported film contains smaller grains in the $\mathrm{Pt}-\mathrm{TiO}_{2}$ than in pure $\mathrm{TiO}_{2}$. 
TABLE 1: The values of kinetic coefficient $k$ in four experiments with application of the first-order kinetic model.

\begin{tabular}{lcccc}
\hline ID & Catalyst & Process & Rate constant $\left(\mathrm{min}^{-1}\right)$ & $k$ Correlation coefficient $(\mathrm{R})$ \\
\hline $\mathrm{A}$ & $\mathrm{TiO}_{2}$ & PC & 0.007 & 0.9600 \\
$\mathrm{~B}$ & $\mathrm{TiO}_{2}$ electrode & PEC & 0.011 & 0.9914 \\
$\mathrm{C}$ & $\mathrm{Pt}^{-T i O}{ }_{2}$ & PC & 0.028 & 0.9901 \\
$\mathrm{D}$ & $\mathrm{Pt}^{-\mathrm{TiO}_{2}}$ electrode & PEC & 0.038 & 0.9726 \\
\hline
\end{tabular}

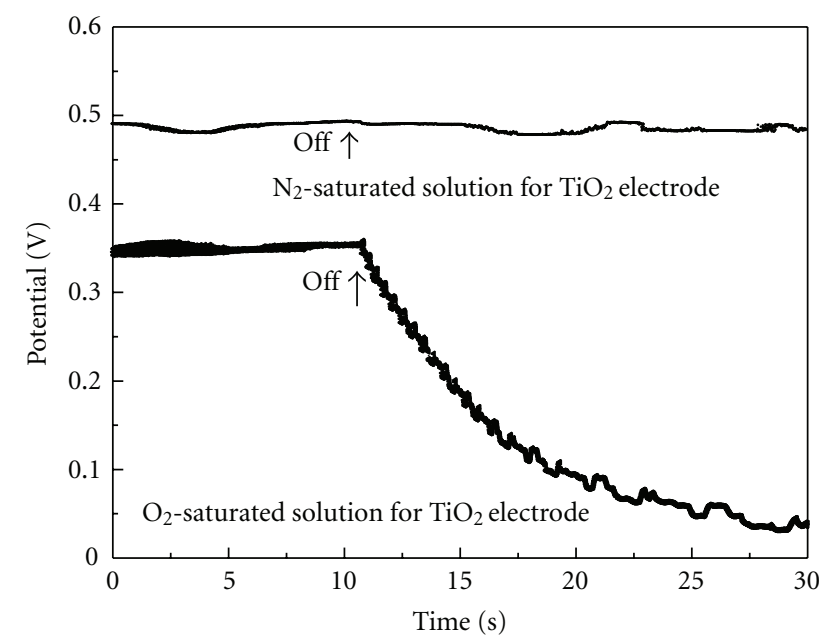

(a)

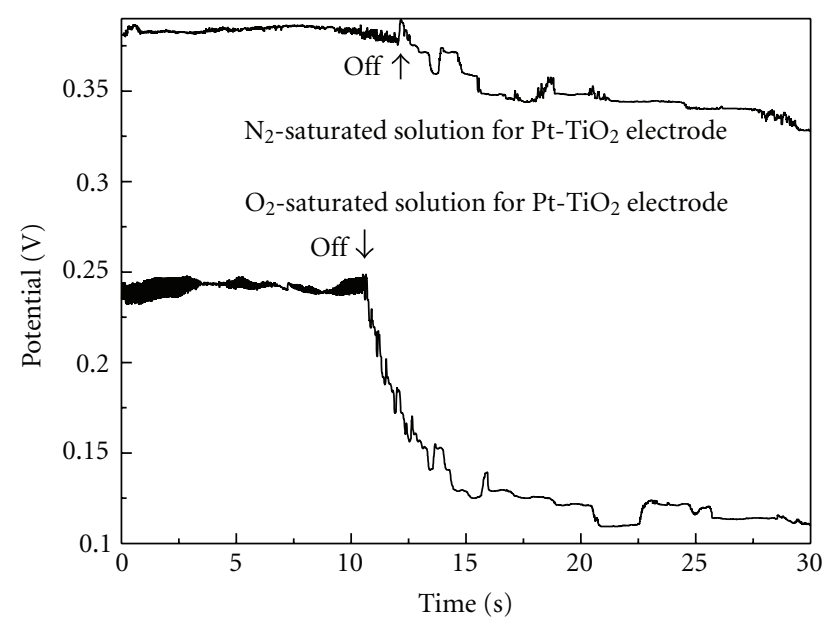

(b)

FIGURE 5: Decay curves of open circuit voltage after light was turned off (a) $\mathrm{TiO}_{2}$ film and (b) $\mathrm{Pt}-\mathrm{TiO}_{2}$.

3.2. Photoelectrochemical Characterization of $\mathrm{Pt}-\mathrm{TiO}_{2}$ Film. The dependence of photovoltage of $\mathrm{Pt}-\mathrm{TiO}_{2}$ film on Pt content in $\mathrm{N}_{2}$-or $\mathrm{O}_{2}$-saturated solution is showen in Figure 4. In the dark, the Fermi level of a semiconductor film equilibrates with the redox couple in solution; upon excitation of $\mathrm{TiO}_{2}$ film, the photogenerated electrons accumulate in the $\mathrm{TiO}_{2}$ particulate film, leading to a rise in the photovoltage. As a result, any accumulation of electrons in the film will present a rise in $V_{\mathrm{oc}}$. The observation that $V_{\mathrm{oc}}\left(\mathrm{O}_{2}\right)$ of $\mathrm{Pt}-\mathrm{TiO}_{2}$ film in $\mathrm{O}_{2}$-saturation solution is lower than that in $\mathrm{N}_{2}$-saturated

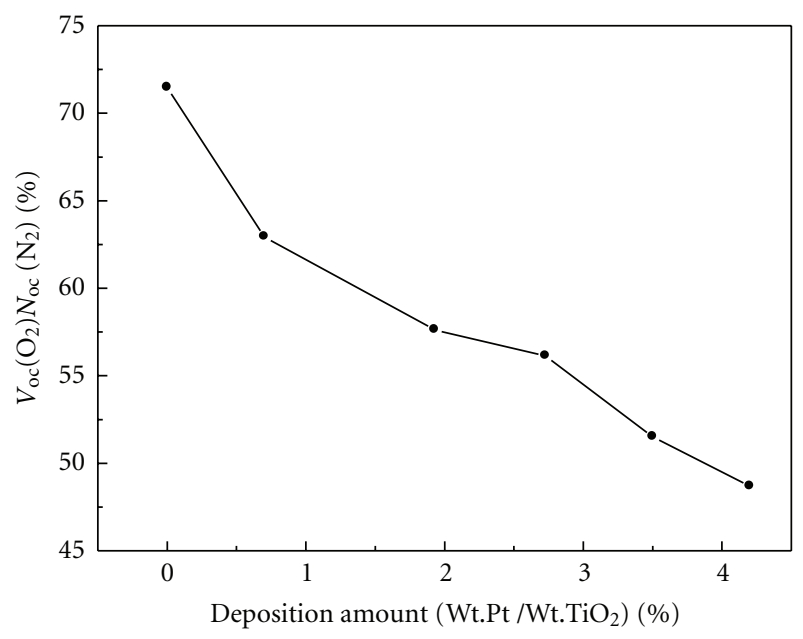

Figure 6: Dependence of $\left[V_{\mathrm{oc}}\left(\mathrm{O}_{2}\right) / V_{\mathrm{oc}}\left(\mathrm{N}_{2}\right)\right]$ on deposited $\mathrm{Pt}$ amount.

solution confirms the fact, due to the surface-adsorbed $\mathrm{O}_{2}$ scavenging the photogenerated electrons in the $\mathrm{O}_{2}$-saturated solution. In addition to the above evidence, it is noting that in either $\mathrm{N}_{2}$ - or $\mathrm{O}_{2}$-saturated solution for $\mathrm{Pt}_{-} \mathrm{TiO}_{2}$ film, $V_{\text {oc }}$ decreases with increase of $\mathrm{Pt}$ content. Generally, $\mathrm{TiO}_{2}$ electrode deposited metallic nanoparticles shifts the photovoltage to more positive value, ascribing to the fact that the metallic nanoparticles improve the accumulation of electrons within the particulate film by facilitating the hole transfer at the electrolyte interface $[7,24]$. An alternative explanation for the above-observed decrease of $V_{\text {oc }}$ was based on the consideration while metal nanoparticles are surrounded by electron donors, and these deposited Pt can diminish the accumulation of photogenerated electrons. We attribute decrease of $V_{\mathrm{oc}}$ to the two tentative factors. Firstly, the deposited $\mathrm{Pt}$ can facilitate the reactions of scavenging photogenerated electrons, such as, $\mathrm{O}_{2}$ reduction (1) and $\mathrm{H}_{2}$ evolution (2):

$$
\begin{aligned}
& \mathrm{O}_{2}+\mathrm{e}=2 \mathrm{O}^{-\bullet} \\
& 2 \mathrm{H}^{+}+\mathrm{e}=\mathrm{H}_{2}
\end{aligned}
$$

Figure 5 clearly shows that, after UV light turns off, the $V_{\mathrm{oc}}$ of $\mathrm{Pt}-\mathrm{TiO}_{2}$ film decreases more rapidly than that of $\mathrm{TiO}_{2}$ film, either for $\mathrm{N}_{2}$-saturated solution or for $\mathrm{O}_{2}$-saturated solution, suggesting that deposited $\mathrm{Pt}$ can facilitate the reactions of scavenging photogenerated electrons for $\mathrm{Pt}-\mathrm{TiO}_{2}$ film via the reactions (1) and (2). 


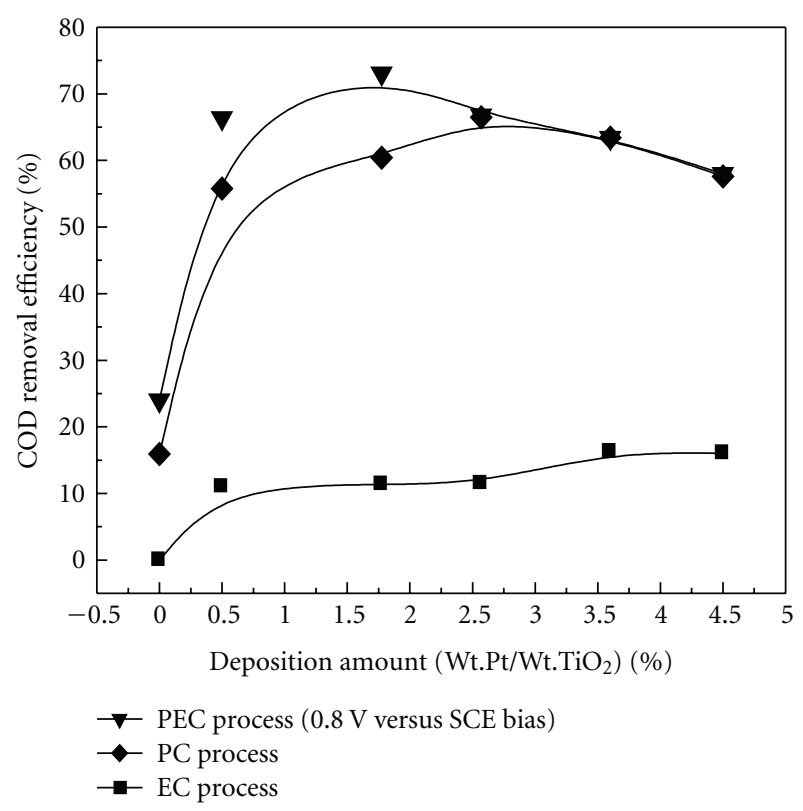

Figure 7: Dependence of COD removal efficiency on deposited Pt amount.

At the same time, it is also seen from Figure 5 that, compared with $\mathrm{O}_{2}$-saturated solution, all the $V_{\text {oc }}$ for $\mathrm{N}_{2}$ saturated solution merely decreases slightly, indicating that the capture of electrons is mainly by the reaction (1), not (2). Therefore, the fraction of the remained photogenerated electrons on the platinised film can be approximately estimated by $V_{\text {oc }}\left(\mathrm{O}_{2}\right) / V_{\text {oc }}\left(\mathrm{N}_{2}\right)$ [28]. The estimated results (Figure 6) suggested that there are still rather remained accumulated electrons on $\mathrm{Pt}-\mathrm{TiO}_{2}$ film in the experimental range although $\mathrm{Pt}$ deposition can increase the efficiency of the charge separation. For example, for $\mathrm{Pt}-\mathrm{TiO}_{2}$ film with $0.7 \% \mathrm{Pt}$ content, the fraction of the remained electrons is $63 \%$. Therefore, it is reasonable to employ an anodic bias to drive away the remained accumulation electrons in order to increase PC efficiency.

3.3. PC and PEC Oxidation of Pt-TiO ${ }_{2}$ Film. The PC and PEC oxidation activities of $\mathrm{Pt}-\mathrm{TiO}_{2}$ films towards formic acid were evaluated in the term of COD removal efficiency in the present investigation. Presently, the influence of $\mathrm{Pt}$ content concentration on COD removal efficiencies is studied in a range from 0 to $4.5 \%$ not only for PC process but also for electrochemical and PEC processes. As shown in Figure 7, respectively, the COD removal efficiency is dependent on the amount of the $\mathrm{Pt}$ content for both $\mathrm{PC}$ and PEC processes, while the COD removal efficiency of electrochemical (EC) process changes slightly with $\mathrm{Pt}$ content. For PC processes, the COD removal efficiencies increase with the Pt content in the range of $0 \% \sim 2.7 \%$. The enhancement effect further shows that Pt serves as an electron trapper and reduces the recombination of hole-electron pairs. However, over-deposited Pt resulted in a decrease in PC activity due to the reason that the cluster or aggregation of metal deposits on the surface changes the function

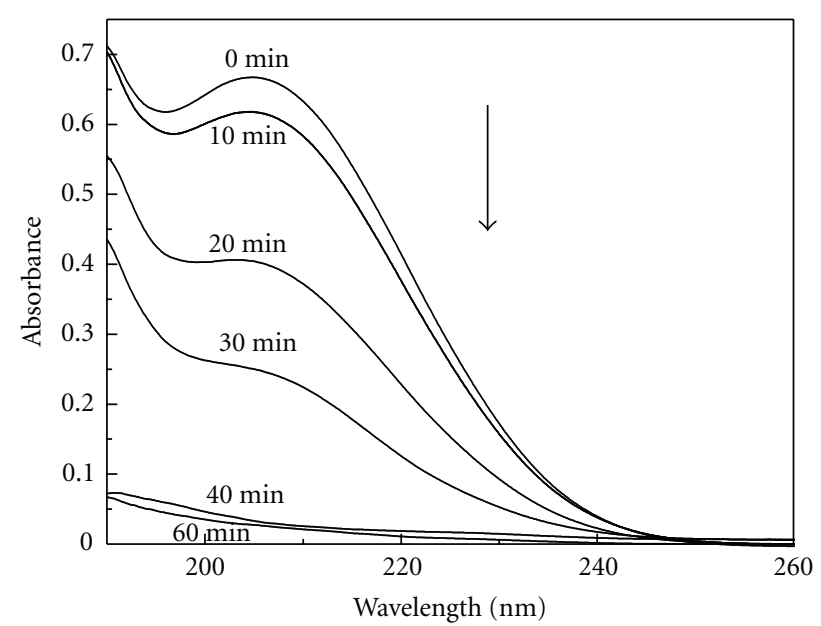

FIgURE 8: Change of UV spectra of formic acid at various reaction intervals for PEC process in the presence of $0.8 \mathrm{~V}$ versus SCE anodic bias.

from an electron separation center to an electron recombination center and consequently reduced the PC activity [29].

For PEC process, a similar change tendency was observed. However, it was also found that the COD removal efficiency for PEC process is considerably higher than that of PC process. For example, in the absence of $\mathrm{Pt}$, the COD removal efficiency of PEC process is $24.0 \%$ while that of PC process is only $15.9 \%$. For $\mathrm{TiO}_{2}$ film with a $\mathrm{Pt}$ content of $1.7 \%$, the COD removal efficiency of the PEC process is $73.4 \%$ while that of $\mathrm{PC}$ process is $60.4 \%$, higher than the sum the COD removal efficiency for individual PC process $(60.4 \%)$ and electrochemical process (11\%). The observations denote that there is a significant synergistic effect existing in the PEC process.

In addition, the difference between PEC and PC processes on $\mathrm{Pt}-\mathrm{TiO}_{2}$ films with a Pt content of $1.7 \%$ is $13 \%$, higher than that for neat $\mathrm{TiO}_{2}$ film $(8 \%)$, indicating that the enhancement effect of the external electric field in the presence of $\mathrm{Pt}$ is more obvious than in the absence of Pt. The more obvious enhancement effect can be explained by the fact that the $\mathrm{Pt}$ can not only trap the photogenerated electrons but also assist the external electric field to migrate them from the $\mathrm{TiO}_{2}$ film to counter electrode in another compartment of the cell by improving electric conductivity of $\mathrm{TiO}_{2}$ film as well as decrease the recombination. For either $\mathrm{PEC}$ or PC process, the $\mathrm{Pt}-\mathrm{TiO}_{2}$ films with $\mathrm{Pt}$ content of $1.7 \%$ possess a relative good performance of COD removal, all the rest of our experiments was conducted using the $\mathrm{Pt}-\mathrm{TiO}_{2}$ films with Pt content of $1.7 \%$.

3.4. Comparison of Rate Constants for PC or PEC Processes. The UV spectra of formic acid in the PEC process at various reaction intervals are presented in Figure 8. It can be observed from the figure that formic acid decreased dramatically. And the COD removal efficiencies, at any tested time, are much higher than that for either PC process on Pt$\mathrm{TiO}_{2}$ film or PEC process on $\mathrm{TiO}_{2}$ film as shown in Figure 9. 


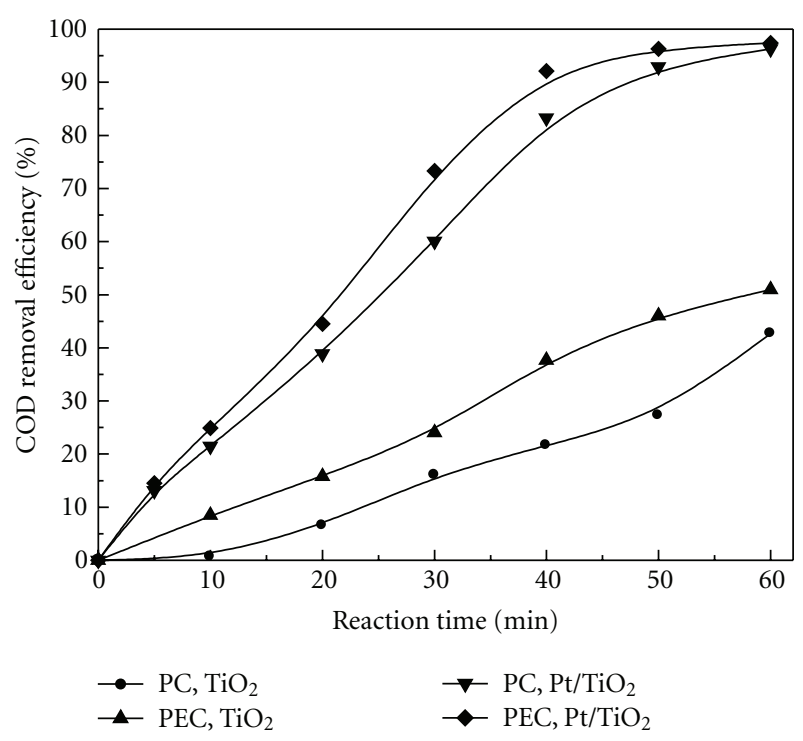

Figure 9: Dependence of COD removal efficiency on treatment time for various processes.

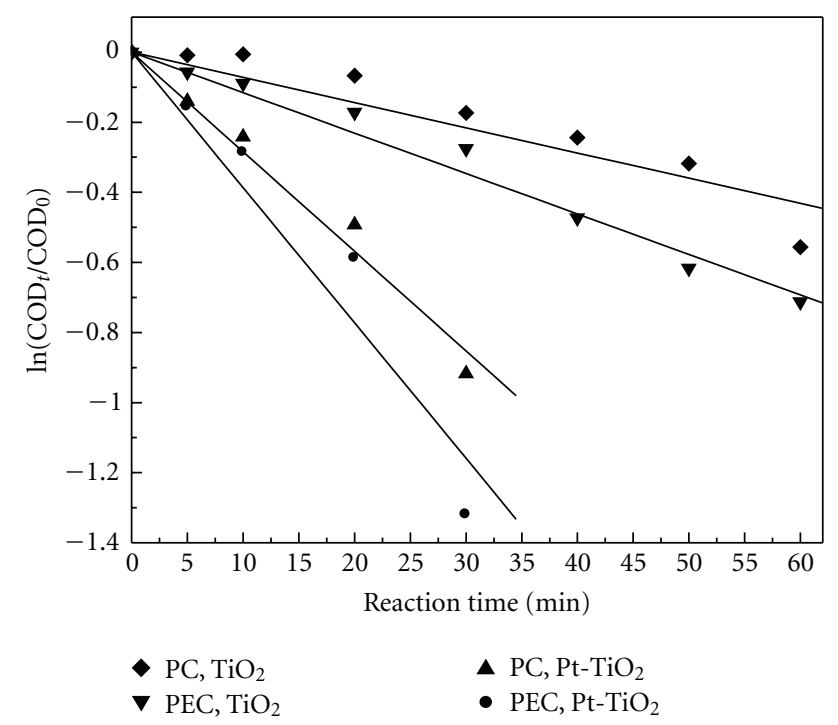

FIGURE 10: Logarithm of formic acid normalized COD concentration as a function of treatment time for the four processes.

It is also well recognized that PC degradation of organic pollutants accords with the first-order kinetics [30-32]. In this work, the first-order kinetics were also confirmed not only in the PC but also in the PEC process by the linear transforms $\ln \left(\mathrm{COD} t / \mathrm{COD}_{0}\right)=-k t$ of Figure 9 as shown in Figure 10. The kinetic regression equations and parameters were listed in Table 1; the rates for the PC oxidation or the PEC oxidation on $\mathrm{Pt}-\mathrm{TiO}_{2}$ film electrode are more than 4 times or 5.4 times of the PC oxidation on $\mathrm{TiO}_{2}$ film, respectively. The observation further confirms that the combination of Pt deposition and the application of external electric field had a beneficial effect on enhancing the efficiency of the PC oxidation of formic acid.

\section{Conclusion}

The feasibility of improving the PC activity of $\mathrm{TiO}_{2}$ film towards the oxidation of organic pollutant by combining the modification of $\mathrm{Pt}$ nanoparticles with the application of anodic bias was investigated. In this experiment Pt-TiO films were used as photoanodes in a two-compartment photoelectrochemical cell to investigate its photoelectrochemical performance and the PEC activity towards the oxidation of formic acid. The experimental results showed that the deposited Pt has an apparent enhancement effect with respect to suppressing the recombination between the photogenerated charge carriers and enhancing the PC oxidation of formic acid, and the PC and PEC activities of $\mathrm{Pt}-\mathrm{TiO}_{2}$ film towards the oxidation of formic acid were considerably dependent on the amount of deposited Pt. Compared with a $\mathrm{TiO}_{2}$ film, the degradation efficiency of formic acid on the $\mathrm{Pt}-\mathrm{TiO}_{2}$ films increased markedly in both the PC and PEC oxidation processes.

\section{Acknowledgments}

The authors wish to thank for the financial support to this work from the National Natural Science Foundation of China (no. 20877025), the Specialized Research Fund for the Doctoral Program of Higher Education of China Education Ministry (no. 200805611015), and the Scientific Research Foundation for the Returned Overseas Chinese Scholars, State Education Ministry.

\section{References}

[1] G. Ceńti, P. Ciambelli, S. Perathoner, and P. Russo, "Preface: outlooks for environmental catalysis," Catalysis Today, vol. 75, no. 1-4, pp. 1-2, 2002.

[2] D. Simonsson, "Electrochemistry for a cleaner environment," Chemical Society Reviews, vol. 26, no. 3, pp. 181-189, 1997.

[3] A. Fujishima, T. N. Rao, and D. A. Tryk, "TiO 2 photocatalysts and diamond electrodes," Electrochimica Acta, vol. 45, no. 28, pp. 4683-4690, 2000.

[4] D. A. Tryk, A. Fujishima, and K. Honda, "Recent topics in photoelectrochemistry:achievements and future prospects," Electrochimica Acta, vol. 45, no. 15-16, pp. 2363-2376, 2000.

[5] J. C. Yu, J. Lin, and R. W. M. Kwok, "Enhanced photocatalytic activity of Til- $\mathrm{xVxO}_{2}$ solid solution on the degradation of acetone," Journal of Photochemistry and Photobiology A, vol. 111, no. 1-3, pp. 199-203, 1997.

[6] S. Li, G. Ye, and G. Chen, "Low-temperature preparation and characterization of nanocrystalline anatase $\mathrm{TiO}_{2}$," Journal of Physical Chemistry C, vol. 113, no. 10, pp. 4031-4037, 2009.

[7] V. Subramanian, E. Wolf, and P. V. Kamat, "Semiconductormetal composite nanostructures. To what extent do metal nanoparticles improve the photocatalytic activity of $\mathrm{TiO}_{2}$ films?" Journal of Physical Chemistry B, vol. 105, no. 46, pp. 11439-11446, 2001.

[8] D. Hufschmidt, D. Bahnemann, J. J. Testa, C. A. Emilio, and M. I. Litter, "Enhancement of the photocatalytic activity of various $\mathrm{TiO}_{2}$ materials by platinisation," Journal of Photochemistry and Photobiology A, vol. 148, no. 1-3, pp. 223-231, 2002.

[9] Z. Luo, K. Katayama-Hirayama, K. Hirayama, T. Akitsu, and H. Kaneko, "Photocatalytic degradation of pyrene in 
porous $\mathrm{Pt} / \mathrm{TiO}_{2}-\mathrm{SiO}_{2}$ photocatalyst suspension under UV irradiation," Nano, vol. 3, no. 5, pp. 317-322, 2008.

[10] A. Sclafani and J.-M. Herrmann, "Influence of metallic silver and of platinum-silver bimetallic deposits on the photocatalytic activity of titania (anatase and rutile) in organic and aqueous media," Journal of Photochemistry and Photobiology A, vol. 113, no. 2, pp. 181-188, 1998.

[11] F. Boccuzzi, A. Chiorino, M. Manzoli, and D. Andreeva, "Gold, silver and copper catalysts supported on $\mathrm{TiO}_{2}$ for pure hydrogen production," Catalysis Today, vol. 75, no. 1-4, pp. 169-175, 2002.

[12] R. M. Lahtinen, D. J. Fermín, H. Jensen, K. Kontturi, and H. H. Girault, "Two-phase photocatalysis mediated by electrochemically generated Pd nanoparticles," Electrochemistry Communications, vol. 2, no. 4, pp. 230-234, 2000.

[13] F. Sunada and A. Heller, "Effects of water, salt water, and silicone overcoating of the $\mathrm{TiO}_{2}$ photocatalyst on the rates and products of photocatalytic oxidation of liquid 3-octanol and 3-octanone," Environmental Science and Technology, vol. 32, no. 2, pp. 282-286, 1998.

[14] P. S. M. Dunlop, J. A. Byrne, N. Manga, and B. R. Eggins, "The photocatalytic removal of bacterial pollutants from drinking water," Journal of Photochemistry and Photobiology A, vol. 148, no. 1-3, pp. 355-363, 2002.

[15] U. Siemon, D. Bahnemann, J. J. Testa, D. Rodríguez, M. I. Litter, and N. Bruno, "Heterogeneous photocatalytic reactions comparing $\mathrm{TiO}_{2}$ and $\mathrm{Pt} / \mathrm{TiO}_{2}$," Journal of Photochemistry and Photobiology A, vol. 148, no. 1-3, pp. 247-255, 2002.

[16] J. Chen, D. F. Ollis, W. H. Rulkens, and H. Bruning, "Photocatalyzed oxidation of alcohols and organochlorides in the presence of native $\mathrm{TiO}_{2}$ and metallized $\mathrm{TiO}_{2}$ suspensions. Part (I): photocatalytic activity and $\mathrm{pH}$ influence," Water Research, vol. 33, no. 3, pp. 661-668, 1999.

[17] V. Vamathevan, R. Amal, D. Beydoun, G. Low, and S. McEvoy, "Photocatalytic oxidation of organics in water using pure and silver-modified titanium dioxide particles," Journal of Photochemistry and Photobiology A, vol. 148, no. 1-3, pp. 233$245,2002$.

[18] K. Vinodgopal and P. V. Kamat, "Enhanced rates of photocatalytic degradation of an azo dye using $\mathrm{SnO}_{2} / \mathrm{TiO}_{2}$ coupled semiconductor thin films," Environmental Science and Technology, vol. 29, no. 3, pp. 841-845, 1995.

[19] R. Pelegrini, P. Peralta-Zamora, A. R. De Andrade, and J. Reyes, "Electrochemically assisted photocatalytic degradation of reactive dyes," Applied Catalysis B, vol. 22, no. 2, pp. 83-90, 1999.

[20] X. Z. Li, H. L. Liu, P. T. Yue, and Y. P. Sun, "Photoelectrocatalytic oxidation of rose Bengal in aqueous solution using a $\mathrm{Ti} / \mathrm{TiO}_{2}$ mesh electrode," Environmental Science and Technology, vol. 34, no. 20, pp. 4401-4406, 2000.

[21] D. H. Kim and M. A. Anderson, "Solution factors affecting the photocatalytic and photoelectrocatalytic degradation of formic acid using supported $\mathrm{TiO}_{2}$ thin films," Journal of Photochemistry and Photobiology A, vol. 94, no. 2-3, pp. 221229, 1994.

[22] M. V. B. Zanoni, J. J. Sene, and M. A. Anderson, "Photoelectrocatalytic degradation of Remazol Brilliant Orange 3R on titanium dioxide thin-film electrodes," Journal of Photochemistry and Photobiology A, vol. 157, no. 1, pp. 55-63, 2003.

[23] J. Rodriguez, M. Gomez, S. E. Lindquist, and C. G. Granqvist, "Photo-electrocatalytic degradation of 4-chlorophenol over sputter deposited Ti oxide films," Thin Solid Films, vol. 360, no. 1-2, pp. 250-255, 2000.
[24] C. He, Y. Xiong, D. Shu, and X. H. Zhu, "Enhanced photocatalytic efficiency of $\mathrm{TiO}_{2}$ by combining the modification of Ag nanoparticles with the application of anodic bias," Chinese Chemical Letters, vol. 14, no. 5, pp. 539-542, 2003.

[25] C. He, Y. Xiong, and X. Zhu, "Improving photocatalytic activity of $\mathrm{Cu}$-loaded $\mathrm{TiO}_{2}$ film using a pulse anodic bias," Catalysis Communications, vol. 4, no. 4, pp. 183-187, 2003.

[26] Y. Xiong, P. J. Strunk, H. Xia, X. Zhu, and H. T. Karlsson, "Treatment of dye wastewater containing acid orange II using a cell with three-phase three-dimensional electrode," Water Research, vol. 35, no. 17, pp. 4226-4230, 2001.

[27] D. K. Lee and D. S. Kim, "Catalytic wet air oxidation of carboxylic acids at atmospheric pressure," Catalysis Today, vol. 63, no. 2-4, pp. 249-255, 2000.

[28] N. Chandrasekharan and P. V. Kamat, "Improving the photoelectrochemical performance of nanostructured $\mathrm{TiO}_{2}$ films by adsorption of gold nanoparticles," Journal of Physical Chemistry B, vol. 104, no. 46, pp. 10851-10857, 2000.

[29] A. Sclafani and J. M. Herrmann, "Influence of metallic silver and of platinum-silver bimetallic deposits on the photocatalytic activity of titania (anatase and rutile) in organic and aqueous media," Journal of Photochemistry and Photobiology A, vol. 113, no. 2, pp. 181-188, 1998.

[30] J. Matos, J. Laine, and J. M. Herrmann, "Synergy effect in the photocatalytic degradation of phenol on a suspended mixture of titania and activated carbon," Applied Catalysis B, vol. 18, no. 3-4, pp. 281-291, 1998.

[31] T. C. An, X. H. Zhu, and Y. Xiong, "Synergic degradation of reactive brilliant red $\mathrm{X}-3 \mathrm{~B}$ using three demension electrodephotocatalytic reactor," Journal of Environmental Science and Health A, vol. 36, no. 10, pp. 2068-2082, 2001.

[32] T. C. An, X. H. Zhu, and Y. Xiong, "Feasibility study of photoelectrochemical degradation of methylene blue with threedimensional electrode-photocatalytic reactor," Chemosphere, vol. 46, no. 6, pp. 897-903, 2002. 


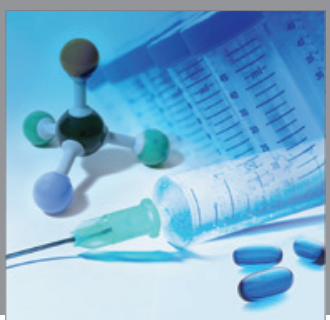

International Journal of

Medicinal Chemistry

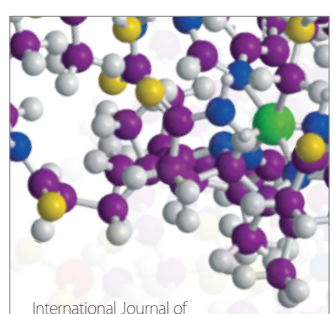

Carbohydrate Chemistry

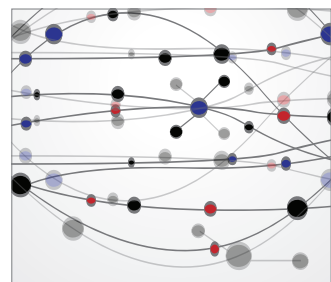

The Scientific World Journal
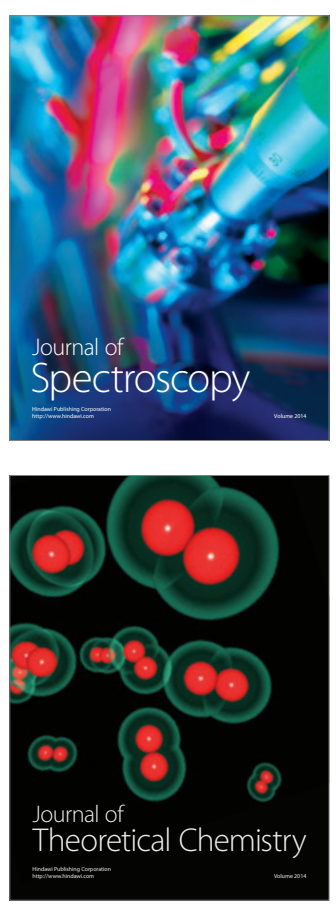
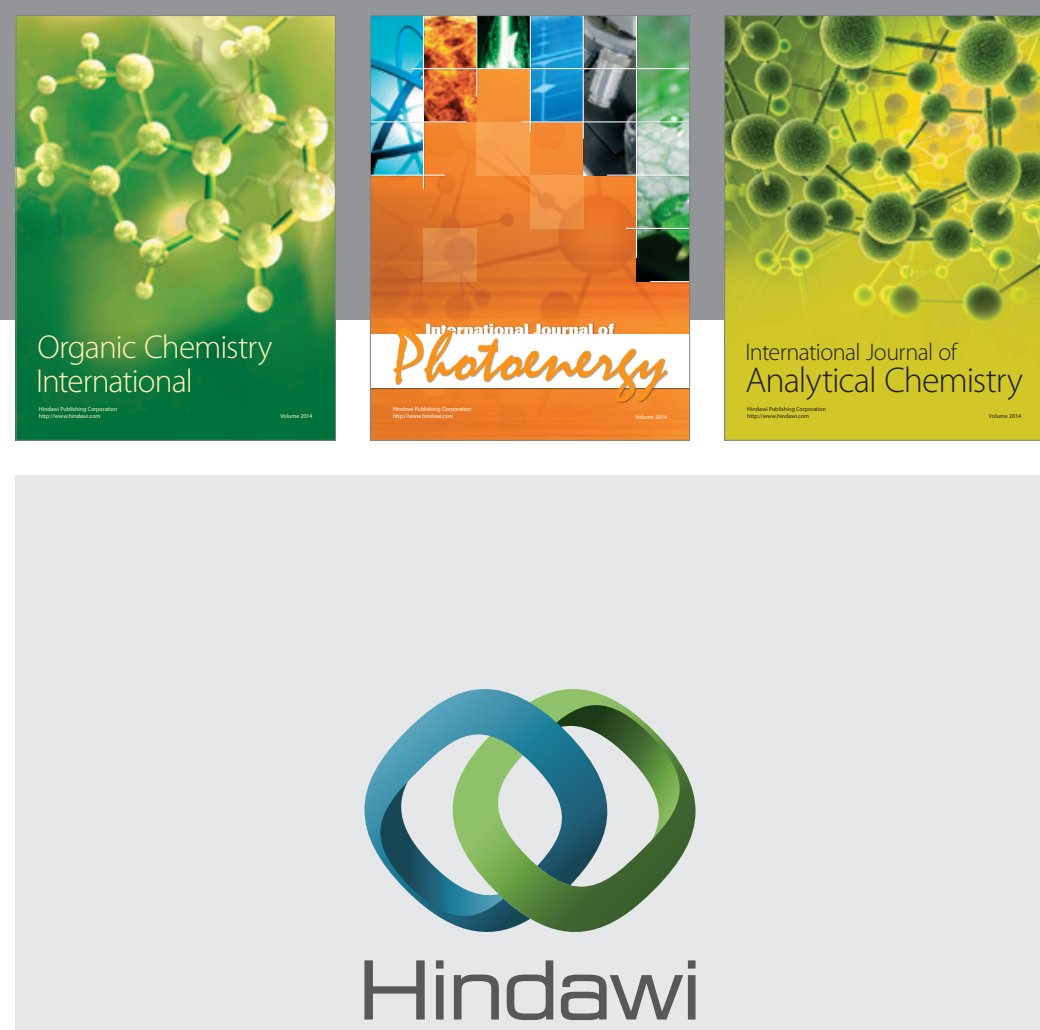

Submit your manuscripts at

http://www.hindawi.com
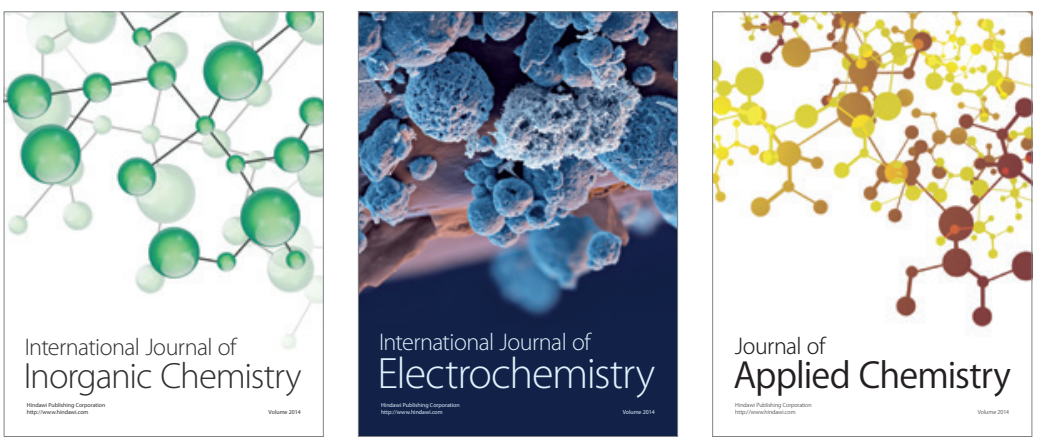

Journal of

Applied Chemistry
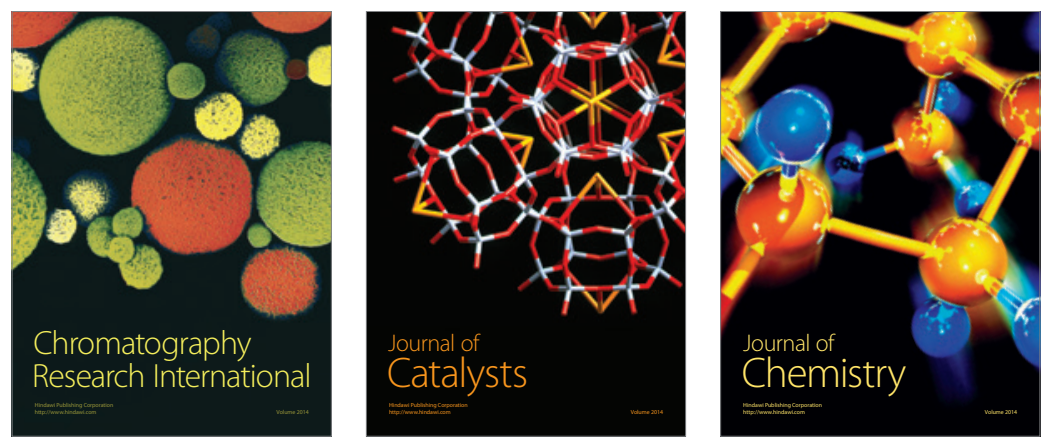
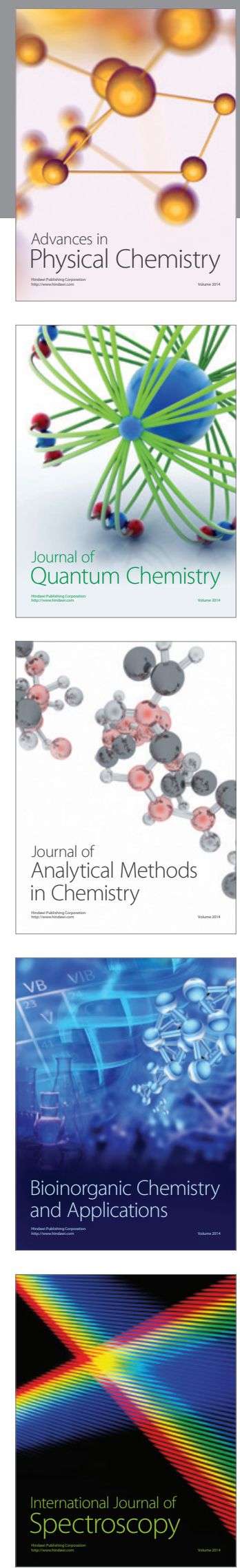